\title{
Estabelecendo relações entre as dimensões pedagógica e epistemológica no Ensino de Ciências
}

\author{
Establishing relations between the pedagogical \\ and epistemological dimensions in Science Teaching
}

\author{
Erivanildo Lopes Silva ${ }^{1}$ \\ https://orcid.org/0000-0003-2207-8661 \\ Edson José Wartha ${ }^{1}$ \\ https://orcid.org/0000-0003-4919-3504
}

\begin{abstract}
Resumo: Neste estudo discutiremos aspectos epistemológicos e pedagógicos fulcrais e subjacentes ao delineamento de Sequências de Ensino e Aprendizagem no âmbito do ensino de Ciências, sobretudo destacando a abordagem desses materiais na escola secundária. Tal delineamento está embasado em um modelo didático que considera elementos das relações conceito-contexto, na dimensão epistêmica, estudante-professor, na dimensão pedagógica. Embasados nesse modelo, defendemos que essa estrutura pode ser útil tanto para pesquisadores (escolhas e hipóteses mais explícitas) e professores (organização mais dialógica no processo de ensino e aprendizagem) no que tange a pesquisa e o ensino de Ciências.
\end{abstract}

Palavras-chave: Ensino de ciências. Contexto e conceito. Sequências de ensino e aprendizagem.

\begin{abstract}
In this study we will discuss the epistemological and pedagogical aspects that are central to the design of teaching-learning sequences (TLS) in the field of science teaching, especially highlighting the approach of these materials in secondary school. This design is based on a didactic model that considers elements of concept-context relations in the epistemic dimension, and student-teacher in the pedagogical dimension. Based on this model, we defend this structure as useful both for researchers (choices and more explicit hypotheses) and teachers (more dialogic organization in the teaching and learning process) in the research and teaching of science.
\end{abstract}

Keywords: Science teaching. Context and concept. Teaching-learning sequences.

\footnotetext{
${ }^{1}$ Universidade Federal de Sergipe (UFS), Departamento de Química, Programa de Pós-Graduação em Ensino de Ciências e Matemática - PPGECIMA, São Cristóvão, SE, Brasil. E-mail: <erivanildolopes@gmail.com>.
} 


\section{Introdução}

O que se espera do ensino de Ciências na sala de aula? Esta pergunta pode abarcar um espectro bem considerado de respostas. Poder-se-ia escrever diversas teses sobre ensino, sobre aprendizagem ou sobre os processos de ensino e de aprendizagem, contudo defendemos que o debate acerca de proposições para o ensino de Ciências precisa ser mais pontual e taxativo no que tange as seguintes questões: na sala de aula o que se faz, como se faz, qual o propósito de ensinar? O que se aprende de fato? Quais expectativas de aprendizagem são, de fato, intencionais? Como é possível tecer relações entre o ensinar e o aprender no ensino de Ciências?

Tomando como foco de discussão o ensino de Ciências na ação intencional de ensinar, podemos olhar para este processo também no âmbito dos sujeitos que praticam a ação. Desse modo, podemos discutir o ensino com viés do que nós professores podemos fazer, sobretudo, na sala de aula, do Ensino Básico, tratando da Química, Ensino Médio.

Desse modo, a discussão pode ser pensada do ponto de vista do ensinar ciência por pessoas para que pessoas possam interpretar questões do mundo, o que foge do ensino utilitarista do conhecimento servir para algo e também daquele que esgota a tradicional relação canônica de conteúdos (MALDANER, 2003). Então, não se trata de pensar propostas metodológicas para se "passar" conceitos em sala de aula e sim propor uma discussão do que os professores podem considerar na construção de perspectivas de ensino para seus estudantes na sala de aula e sobre suas expectativas de aprendizagem.

Prevalecendo esta visão de tratar o ensino para que pessoas interpretem questões de mundo, as relações no processo de ensino e de aprendizagem de ciências pressupõem a discussão preliminar sobre o "lugar" das relações com o saber. Para Charlot (2000), o saber é uma forma de representação de uma atividade, de relações do sujeito com o mundo, com ele mesmo e com outros. Assim, não há saber que não esteja inscrito em relações de saber. Charlot (2000) assume que a educação deveria ter como objeto os processos que levam o sujeito a adotar uma relação com o saber e não apenas a acumulação de conteúdos intelectuais.

Reforça-se a ideia que no campo intencional, o ensino, no que tange ações pensadas para sala de aula, deve destacar que relações entre os saberes são estabelecidas, sobretudo, evidenciando que a interação destes pode resultar em um constructo que contribua para indivíduos interpretarem questões do mundo. Charlot (2005) defende que a relação com o saber é que o indivíduo busque apreender o mundo de modo a se construir e se transformar considerando o sujeito humano, social e singular. Assim posto, a existência de um ser que é também social e epistêmico possibilita o estabelecimento das relações com o saber.

Entender a relação epistêmica que o estudante possui com o saber é entender a natureza da atividade que se denomina "aprender" para esse sujeito. A relação com o saber também é uma relação social, já que exprime as condições sociais do indivíduo e as relações sociais que estruturam a sociedade que esse indivíduo está inserido. No entanto, Charlot (2000, p. 62) coloca que "[...] as relações sociais estruturam a relação com o saber e com a escola, mas não a determinam". E, por fim, a relação com o saber também é uma relação de identidade com o saber. Todo processo de "aprender" constitui uma construção de si mesmo, uma construção da identidade do sujeito. Assim, analisar a relação de um sujeito com o saber é entender as relações epistêmicas, sociais e identitárias do sujeito imerso no processo de aprendizagem, sendo que essas dimensões não estão fragmentadas nesse processo. Essas relações ocorrem simultaneamente. 
Se as demandas sociais, identitárias e epistêmicas são importantes para que os alunos possam aprender, então se faz necessário explorar estas questões no ensino de Ciências. Assim posto, pode-se assumir que existe uma relação entre os saberes dos estudantes, dos saberes apresentados na escola e, daqueles, existentes no mundo material (eminentemente social).

\section{Aprofundamento Teórico}

Uma forma de levar de algum modo essas as demandas sociais, identitárias e epistêmicas para sala de aula é fazer uma reflexão sobre outras duas relações que consideramos fundamentais nos processos de ensino que resulte em possíveis aprendizagens em ciências, que são as dimensões epistêmicas e pedagógicas (MÉHEUT, 2005).

$\mathrm{Na}$ dimensão epistêmica, de acordo com Méheut (2005), leva-se em consideração a relação existente entre o mundo material (contextual) e conhecimento científico (conceitual), considerando nessa relação uma Ciência em função de um mundo holístico, complexo e histórico-social dos sujeitos (estudantes e professores). Assim, a escolha de uma situação problema, por exemplo, vincula-se à dimensão epistêmica, pois reflete-se como o professor lida com a contextualização do conhecimento científico. Na dimensão didático-pedagógica observa-se a relação entre professor e estudante, pois se relaciona mais com a forma que o professor estabelece o diálogo com os alunos, como ocorrem as relações professor/aluno e aluno/aluno.

A ideia destas duas dimensões é defendida Méheut e Psillos (2004) e podem ser apresentadas por meio do Modelo de Losango Didático dos autores. Retratando a interação entre esses nos processos de ensino e de aprendizagem conforme esquema da Figura 1.

Figura 1. Relações epistêmicas e pedagógicas nos processos de ensino e de aprendizagem

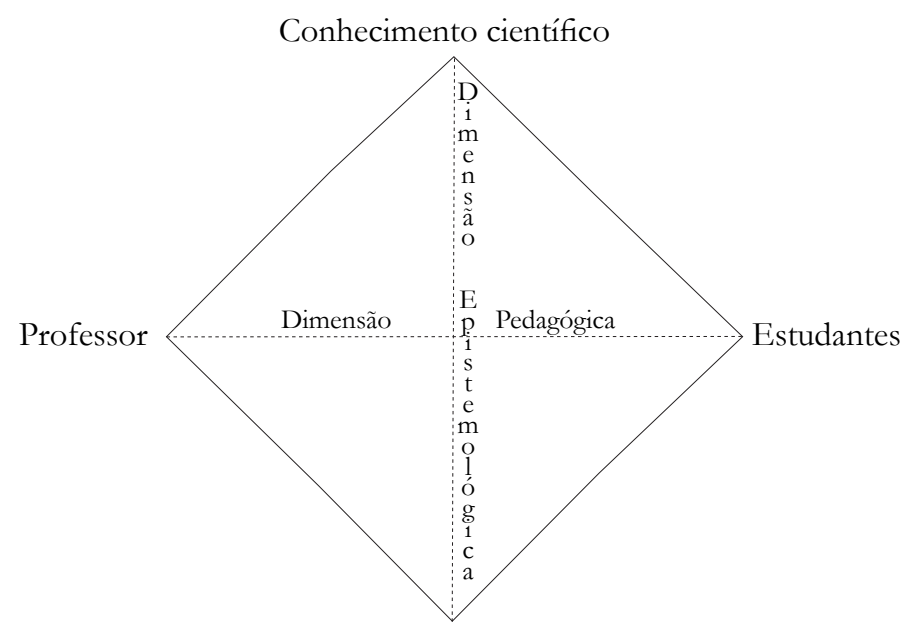

Mundo material

Fonte: Adaptado de Méheut e Psillos (2004). 
Os estudos de Méheut (2005) sugerem considerar conjuntamente as dimensões epistêmica e pedagógica, numa perspectiva que denomina Construtivista Integrada, já que segundo a autora, tanto o conhecimento a ser desenvolvido como os sujeitos envolvidos são igualmente importantes nesse processo e por possibilitar ao estudante encontrar sentido na atividade de ensino e no conteúdo (ou método) a ser aprendido. Para Charlot (2000) esse sentido se dá nas relações com o saber, principalmente, na relação com os significados e sentidos a ele conferidos, como por exemplo, com os elementos não intelectuais (socioemocionais) do sujeito social singular, inserido em um contexto social, cultural e histórico.

Esta dimensão abrange questões como o estudo da natureza do conhecimento, como ele foi gerado historicamente, problemas relacionados ao ensino e aprendizagem desse conhecimento. Verificar também o grau de complexidade dos conceitos a serem abordados, as análises prévias devem considerar a epistemologia dos conceitos científicos envolvidos, o trato com as concepções prévias dos alunos, a busca da superação das dificuldades e de possíveis obstáculos à aprendizagem.

Ainda nessa dimensão, a abordagem em sala de aula deve estar apoiada em recursos didáticos que consideram uma análise prévia dos conhecimentos espontâneos dos alunos, das possíveis concepções alternativas que eles apresentam. Considera-se também a análise das situações de ensino e possíveis aprendizagens, das estratégias adotadas, do grau de importância para os estudantes tanto dos conceitos quanto das formas de abordagem com eles e, principalmente, prever seus comportamentos frente a tais situações.

$\mathrm{Na}$ dimensão pedagógica percebe-se um viés que considere atividades com potencial para o professor possibilitar a discussão entre os alunos, que tenham a oportunidade de pesquisar e discutir a temática em diferentes pontos de vista. Um momento propício para que ocorra maior grau de interação entre estudantes e professor. Sobre as interações em sala de aula, de acordo com o modelo do Losango de Méheut e Psillos (2004), no qual estabelece uma interconexão com a relação contexto (mundo material) - conceito (conhecimento científico), a de considerar a participação ativa dos estudantes na construção coletiva dos discursos em sala de aula (SOUZA; MARCONDES, 2013).

Abordagens em sala de aula que procuram estabelecer a relação contexto-conceito apresentam grande potencial de possibilitar de modo mais intensificado de interações cognitivas mais elaboradas, aquelas de ordem alta de cognição. Significa dizer que aulas mais contextualizadas possibilitam que ocorram um número maior de interações entre professor e alunos, tornando a aula mais dialógica e potencialmente promotora de aprendizagens (SOUZA; MARCONDES, 2013). Esses autores argumentam ainda que aulas contextualizadas permitem que a relação contexto-conceito ocorra de acordo com um nível mais elaborado de contextualização, aquela que presume minimante a compreensão de processos tecnológicos com vistas à transformação da realidade social por meio da reflexão crítica de questões técnico-científicas socialmente relevantes.

Após esse preâmbulo, percebe-se que as dimensões epistêmica e pedagógica abrem diferentes possibilidades para os processos de ensino e aprendizagem de conceitos científicos no contexto da sala de aula. Tratando da dimensão epistêmica, Conceito-Contexto, entende-se que o conhecimento científico deve estar posto em função de sua relação com o mundo material, com toda a complexidade do seu cotidiano, abrindo diferentes possibilidades para discutir as relações entre os saberes do senso comum e os saberes científicos. Fica latente também a relação do sujeito que aprende com os diferentes saberes no processo de construção e elabo- 
ração conceitual de saberes escolares que são reconstruídos por novos sujeitos em diferentes contextos, que podem ser melhor compreendidos na dimensão pedagógica.

De modo a entender mais detidamente os elementos que se aportam sobre as dimensões epistêmica e pedagógica apresentadas no Modelo de Losango Didático (Figura 1) de Méheut e Psillos (2004), será apresentada uma discussão de acordo com elementos relacionados aos processos de ensino e de aprendizagem destacando, mais especificamente, questões do ensino de acordo com os quatro quadrantes existentes no modelo desses pesquisadores. Desse modo, será tratada de relação explícita as duas dimensões destacadas no Losango didático (epistêmica e pedagógica), e implícitas aquelas de acordo com os quadrantes "a", "b", "c" e "d".

No quadrante "a", em que o eixo epistêmico e o eixo pedagógico mostram uma relação implícita entre o professor e o conhecimento científico, é possível discutir e compreender a natureza destas relações. Há várias décadas encontram-se estudos que indicam que os professores apresentam visões distorcidas sobre o trabalho científico e concepções epistemológicas acerca da natureza da ciência e da construção do conhecimento científico, o que leva o ensino de ciências basicamente à apresentação de conhecimentos previamente elaborados, sem dar oportunidade aos estudantes de contatarem e explorarem atividades na perspectiva de um ensino do tipo investigativo (BURBULES; LINN, 1991; CACHAPUZ et al., 2000; HAMMER, 1995; LEDERMAN, 1992; MATTHEWS, 1991; PEREZ et al., 2001; SOLOMON; DUVEEN; SCOTT, 1994; SONGER; LINN, 1991; YAGER; PENICK, 1983).

Grande parte destes estudos indicam que nas aulas de Ciências são transmitidos conhecimentos elaborados sem mostrar quais aspectos lhes deram origem, quais foram suas evoluções e transformações, quais foram as principais dificuldades encontradas para que fossem estabelecidos, quais foram os contextos histórico, cultural e social nos quais foram construídos, ou seja, da maneira como são apresentados não permitem conhecer as limitações destes conhecimentos e, muito menos, as relações que estes estabelecem com o mundo material (contexto). Perde-se assim de vista que, como afirma Bachelard (1996, p. 18), "todo o conhecimento é a resposta a uma pergunta", isto é, a um problema/situação problemática, o que dificulta a captação, bem como a compreensão da racionalidade de todo o processo e empreendimento científicos.

A destacar aqui, que os professores, por conta de vários aspectos que fogem ao seu domínio, optam por apresentar nas salas de aula a relação clássica de conteúdos (MALDANER, 2003). Essa relação implícita tratada do quadrante "a" mostra que o ensino está centrado na transmissão não problematizada dos conhecimentos científicos ainda extremamente preso ao currículo "dente de sabre" (POZO; CRESPO, 2009). Sabe-se que isso é também reflexo de visões distorcidas de ciências que são transmitidas no processo formativo do professor, que são potencializadas pelo descaso com que é tratado esse profissional da educação, o que, em geral, incorrem em um ensino numa visão a-problemática, a-histórica, rígida, infalível, indutivista e a-teórica referendada em inúmeros livros didáticos (FERNANDEZ, 2000).

No quadrante "b", os eixos epistêmico e pedagógico mostram a relação implícita entre o conhecimento científico e o estudante, é possível discutir a questão das concepções alternativas, suas possíveis causas, consequências no processo de aprendizagem de conceitos científicos. Também, é possível encontrar na literatura durante as últimas décadas vários estudos sobre as concepções alternativas. Pozo e Crespo (1998) nos colocam que o estudo sobre as concepções alternativas se têm constituído uma linha de pesquisa dentro da Didática das Ciências. No ensino praticado nas salas de aula, muitas vezes, as concepções dos estudantes, sejam elas prévias ou 
alternativas, não são consideradas, o que acarreta um distanciamento entre o que o estudante sabe e o que trata o conhecimento científico.

As pesquisas de Driver (1981), Viennot (1979), e Watts e Zylberstajn (1981) foram pioneiras sobre concepções alternativas e chamaram tais noções de "conceitos espontâneos", "intuitivos", "formas espontâneas de raciocínio", "estruturas alternativas" e outras denominações semelhantes. Driver (1989) verificou que essas noções podem diferir substancialmente da ciência que se pretende ensinar, que influenciam a aprendizagem futura e que podem ser resistentes a mudanças.

A maior contribuição do movimento das Concepções Alternativas foi trazer a pesquisa em ensino de Ciências para a sala de aula, possibilitando a compreensão das necessidades do professor e das especificidades do ensino de conteúdos relativos à Ciência (MACHADO, 1999). Alguns estudos apontam que uma parte substancial das concepções alternativas dos estudantes derivam do entendimento que constroem a partir dos conceitos anteriormente ensinados (TABER, 2001). Assim, tornava claro que os chamados modelos de aprendizagem por aquisição conceitual, centrados na transmissão de conhecimentos por parte do professor e não no respeito aos conhecimentos prévios dos estudantes não permitiam uma aprendizagem eficiente de Ciências.

Ainda com base na figura, no quadrante "c", cujos eixos pedagógico e epistêmico mostram a relação implícita entre o professor e o mundo material, é possível realizar uma discussão sobre o chamado "ensino do cotidiano", que na maioria das vezes se limita a trazer exemplos de materiais químicos de uso diário ou ainda apresentar citações dos fatos ou processos, como por exemplo aqueles envolvidos no funcionamento dos aparelhos eletroeletrônicos ou daqueles que indicam algum processo industrial de produção. Wartha, Silva e Bejarano (2013), apoiados em Lutfi (1997), afirmam que um ensino de ciências que contemple apenas aspectos dessa natureza seria puramente trivial, prevalecendo apenas o enfoque conceitual. Essa seria uma forma de "dourar a pílula", "motivar os alunos com curiosidades", "buscar ilustrações para o assunto que se está desenvolvendo", ou seja, de introduzir alguma aplicação apenas para disfarçar a abstração excessiva de um ensino puramente conceitual, deixando, à margem, os reais problemas sociais.

Lutfi (1988) também lembra que para trabalhar com o mundo vivido e a partir de problemas sociais não pode implicar em desconsiderar os conteúdos específicos das ciências, as teorias e as concepções científicas não podem ficar de fora. A mesma preocupação é evidenciada ao se pensar em contextualização no ensino de ciências, isso porque trazer para sala de aula diferentes contextos é importante, mas se não forem relacionados aos conceitos científicos tornar-se-ão dispensáveis. Para Auler (2007) os processos de conhecer e intervir no contexto do mundo material não se encontram dissociados.

Como modo de tentar tecer relações mais estreitas Contexto-Conceito, Silva e Marcondes (2015), embasados em Auler (2007), Aikenhead (1994), Delizoicov e Angotti (1991) e Freire (2002), apresentam um modelo que pode servir de base para que os professores planejem materiais didáticos contextualizados com vistas à discussão de questões envolvendo a tríade Ciência, Tecnologia e Sociedade (CTS). De acordo com esse modelo, a construção de materiais didáticos visando a sala de aula deve partir inicialmente de uma situação problema com vistas a compreendê-la com base em conhecimentos científicos pertinentes a aspectos sociais e tecnológicos. O modelo pode ser visto na Figura 2. 
Estabelecendo relações entre as dimensões pedagógica e epistemológica ...

Figura 2. Modelo para elaboração e análises de materiais didáticos de professores

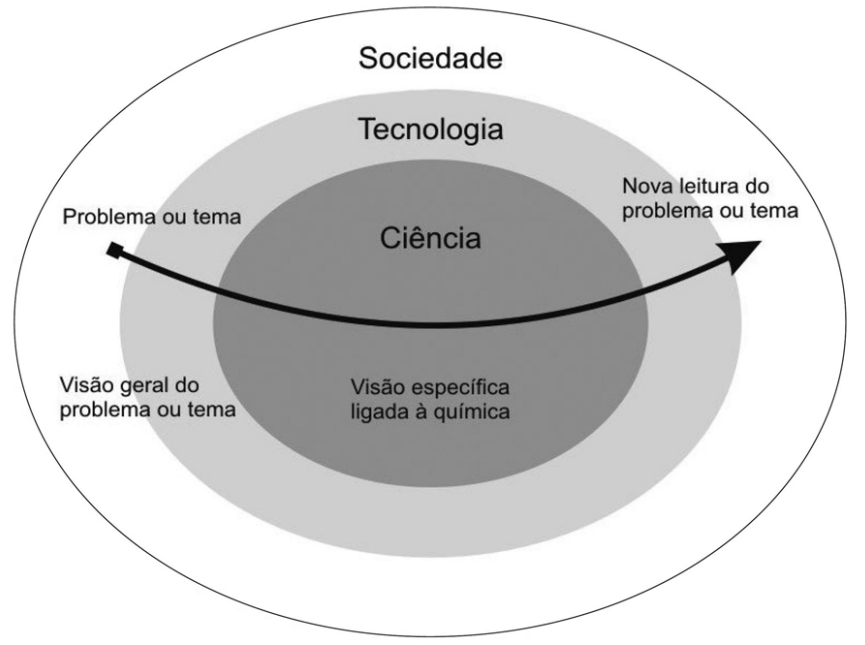

Fonte: Silva e Marcondes (2015).

Tem-se, de início, uma situação problema que deve ser apresentada por meio de questionamentos sobre a temática a ser abordada em aula. Como forma de aproximação com os escritos de Freire, os autores sugerem que sejam desenvolvidas questões junto aos estudantes, isso com vista a pôr em evidência aspectos e contradições do universo temático dos estudantes. Esta etapa é extremante importante, pois é nesta fase que se estabelece a relação de saberes, o saber advindo da Ciência com o dos estudantes.

Percebe-se no modelo a apresentação de uma atividade que possa explorar uma visão geral do problema de modo a permitir análise de informações para entendimento ao problema apresentado. Isso pode ocorrer por meio de textos, vídeos informativos, materiais de internet que possam trazer informações técnicas e termos científicos. Outra parte que o modelo apresenta trata-se do conhecimento científico específico, no caso da área dos autores, Química. Essa é a fase de abordagem conceitual com vistas a responder os questionamentos apresentados, também a relacionar hipóteses e pensamentos dos estudantes com os conhecimentos científicos. Então, após todas as etapas, apresenta-se uma última, uma nova leitura do problema, aquela em que devem ser apresentadas novas situações para que os estudantes possam mobilizar os conhecimentos adquiridos em novas interpretações.

No quadrante "d", no qual o eixo pedagógico e o eixo epistêmico mostram a implicitamente a relação entre o estudante e o mundo material, é possível realizar uma discussão sobre as ideias prévias, os saberes populares, conhecimentos cotidianos de estudantes e suas relações com o conhecimento científico. Teodoro (2000) mostra que existem muitos termos usados pelos pesquisadores no Ensino de Ciências para fazer referência às ideias previamente concebidas pelos estudantes. Dentre os termos, podem ser citados: "conceitos intuitivos", "concepções espontâneas", "ideias ingênuas", "concepções prévias", "pré-conceitos" e "ideias de senso comum”. Driver (1989, p. 483) salienta que os estudantes já chegam nas aulas de Ciências com 
concepções prévias que "podem diferir substancialmente das ideias a serem ensinadas", a ponto de influírem na aprendizagem ou mesmo oferecer resistência a mudanças.

As concepções prévias dos estudantes podem ser tratadas como conhecimentos construídos em meio a vivência social de mundo, se configuram em ideias advindas da leitura primeira que o indivíduo faz do contexto social local e global e, que por vezes, opta por responder os problemas do cotidiano (FLORENTINO, 2004). Na visão freiriana, essas ideias devem servir de base para que o professor pense e repense as ações em sala de aula de modo a interpretá-la por meio do conhecimento sistematizado (SILVA; MARCONDES, 2010).

Temos que levar em consideração que o estudante está o tempo todo imerso neste contexto, ele vive e se relaciona com o mundo material muito antes de aprender Ciências. $\mathrm{O}$ conhecimento científico, embora importante, é uma outra perspectiva de saber, outra forma de relação com o mundo material. Mais uma vez aqui reforça a ideia da aproximação ContextoConceito conforme o modelo de Silva e Marcondes (2015), os Três Momentos Pedagógicos de Delizoivov e Angotti (1991), a Abordagem Temática de Auler (2001), pois considerar a problematização das ideias prévias dos estudantes acaba contribuindo para que a ação de ensino em sala de aula se aproxime cada vez mais do universo social dos estudantes.

Esse detalhamento sobre o Modelo de Losango didático possibilitou verificar uma série de possibilidades e perspectivas apontadas no âmbito do ensino de Ciências que podem contribuir para o professor refletir sobre o processo de ensino em sala de aula. Isso posto, este estudo tem por "obrigação" mostrar a necessidade de construir caminhos e possibilidades para alcançar um equilíbrio possível entre as dimensões epistêmica e pedagógica.

A Figura 3 apresenta o Losango Didático de Méheut e Psillos (2004) com uma pequena modificação, a inserção de uma circunferência no ponto em que os dois eixos se cruzam. $\mathrm{O}$ propósito deste círculo é discutir que existe uma forma de estabelecer um possível equilíbrio em sala de aula, no que tange a relação conhecimento científico-mundo material e aluno-professor.

O professor pode desenvolver abordagens de ensino e conseguir aproximar o conhecimento científico do mundo material na perspectiva de estabelecer relações entre o conceito e o contexto e também uma relação mais dialógica entre professor e estudante. Para tanto é necessário que as estratégias de ensino sejam planejadas intencionalmente para que estas relações ocorram. Isso só será possível com o equilíbrio das relações entre os eixos representadas nos quatro quadrantes se desloquem mais para o centro ou próximo da intersecção entre os dois eixos conforme indica a Figura 3.

O círculo localizado mais ao centro da Figura 3 indica uma zona de aproximação em que as relações implícitas entre as dimensões epistêmicas e pedagógicas são, de nosso ponto de vista, mais favorecidas por permitirem que questões já indicadas nas relações bilaterais nos quatro quadrantes como a questão da natureza do conhecimento científico, das concepções alternativas, do cotidiano e das ideias prévias sejam trazidas para o processo de ensino e de aprendizagem. O desafio, no entanto, é como pensar em estratégias de ensino que permitam essas relações.

Acreditamos que ao aproximar o conhecimento científico e o mundo material no eixo epistêmico é possível a superação de obstáculos à aprendizagem como é o caso de visões distorcidas de ciências, da contextualização trivial com curiosidades do contexto dos estudantes no sentido de "dourar a pílula". Propostas de ensino que buscam uma relação mais acentuada entre conceito e contexto como é o caso da abordagem CTS, abordagem contextualista e abordagem problematizadora apresentam estratégias com diferentes possibilidades de maiores 
relações tanto no eixo epistêmico como no eixo pedagógico, visto que ao aproximarem o mundo material (contexto) do conhecimento científico (conceito), também possibilitam que as relações entre professores e estudantes sejam construídas em relações mais dialógicas.

Figura 3. Aproximação das relações epistêmicas e pedagógicas nos processos de ensino e de aprendizagem

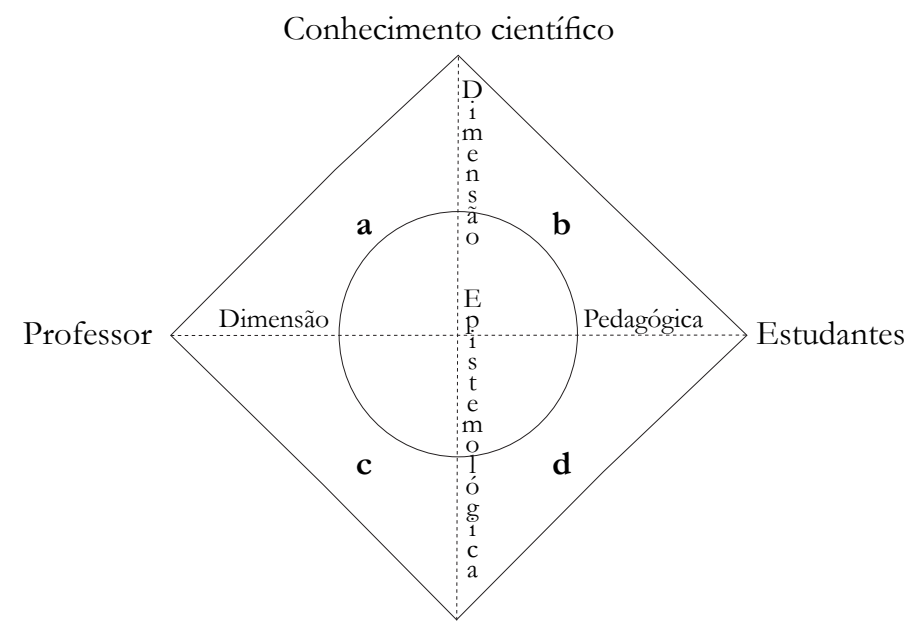

Mundo material

Fonte: Adaptado de Méheut e Psillos (2004) e de Méheut (2005).

Nos quadrantes “a, b, c, d" da Figura 1 e da Figura 3 é possível diferenciar concepções alternativas de concepções prévias, visto que cada uma dessas concepções se estabelece em diferentes formatos de relações. Enquanto que a concepção alternativa se estabelece na relação entre estudante e conhecimento científico, a concepção prévia se estabelece na relação entre o estudante e o mundo material. Esta diferenciação permite que tenhamos clareza sobre o que são estas concepções e de como é possível trabalhar na sala de aula tanto no sentido da ruptura (BACHELARD, 1996) com essas concepções como no sentido da superação (FREIRE, 2005) destas concepções.

O que significa conhecer a estrutura da vida cotidiana, que permeia as classes sociais, de maneira a emergir o extraordinário daquilo que é ordinário, ou seja, buscar naquilo que nos pareça mais comum, mais próximo, o que existe de extraordinário, que foge ao bom senso, e que tem uma explicação que precisa ser desvelada (LUTFI, 2005) nos coloca a questão da cotidianidade. Aqui, novamente um campo imerso de relações possíveis de serem constituídas tanto no eixo epistêmico como no eixo pedagógico. O cotidiano do estudante se apresenta como ordinário e na relação com o professor mediado pelo conhecimento científico é possível extrair o extraordinário, ou seja, uma outra forma de olhar, perceber e conceber o mundo material no eixo pedagógico, teia intensa de relações entre saberes. 
Uma forma de buscar esse equilíbrio entre os eixos epistêmico e pedagógico, tentando aproximações que reflitam numa possível projeção sobre o círculo do modelo do Losango Didático, é o planejamento e construção de materiais didáticos com propostas de ensino que lancem mão de elementos como textos, conceitos, situações problemas, exercícios e a experimentação. Assim, na tentativa de vivenciar abordagens em sala de aula, colocando o ensino de Ciências/Química de acordo com as premissas destacadas em relação as demandas e respectivos eixos epistêmico e pedagógico, apresentamos ações formativas em um curso de Licenciatura em Química de uma IES, através da problematização e validação de Sequências de Ensino Aprendizagem (SEA).

O objetivo dos professores formadores é propiciar aos licenciandos subsídios da vivência da prática para repensarem a elaboração de materiais didáticos, ou seja, possibilitar aos acadêmicos do curso a possibilidade de estudar as análises prévias e variáveis didáticas relacionadas às SEA. Para a elaboração dos materiais didáticos é habitualmente apresentado aos licenciandos o modelo de construção de materiais que pode ser adaptado a abordagem de SEA com base em Méheut e Psillos (2004), levando em consideração os eixos epistêmicos e pedagógicos do modelo do Losango Didático. Assim, são apresentados a eles o modelo para elaboração e análises de materiais didáticos de professores de Silva e Marcondes (2015) e os Três Momentos Pedagógicos de Delizoicov e Angotti (1991).

É sugerido aos licenciandos que problematizassem algum contexto real de relevância social, que explorem aulas experimentais, usem recursos diversos como textos, vídeos por exemplo. E ainda, que lancem mão de diversas estratégias para a aplicação das SEA no contexto de sala de aula na forma de um material sequenciado com a caracterização de cada uma das aulas previamente planejada. Isso permite que professor formador analise esses materiais, verifique diferentes ênfases dadas pelos professores em formação inicial em termos de adoção de inovações pretendidas pelo programa de formação inicial.

Como forma de analisar os materiais didáticos, visando estabelecer o equilíbrio entre os dois eixos didáticos, utiliza-se o seguinte critério: se o material apresenta as relações implícitas entre as dimensões epistêmicas e pedagógicas.

Assim, com base em leituras mais detidas sobre os materiais didáticos, considerando os objetivos propostos e estratégias adotadas em cada aula, é possível estabelecer possíveis projeções destes nos quadrantes do Losango Didático. Dessa forma, pode-se inferir o quanto o material didático se aproxima do Mundo Material e do Conhecimento Científico, tratando do eixo epistemológico. Essa projeção também ocorre no eixo pedagógico, ou seja, aproximações estudante/professor. Tratando dos 4 (quatro) quadrantes, o equilíbrio ocorre quando os elementos constitutivos do material didático se projetam na região da circunferência (Figura 3). Importante frisar que esta projeção é apenas uma estimativa, pois não é necessário tratamento estatístico, esse procedimento é apenas uma forma de problematizar as SEA de acordo com o modelo do Losango Didático.

Considerando as SEA que foram construídas entre os anos de 2014 a 2017, em meio as disciplinas de Estágio Supervisionado em Ensino de Química, em uma Instituição Federal de Ensino Superior, em que foram confeccionados cerca de 25 SEA elaboradas por licenciandos em Química.

Embora essa projeção possa ser realizada em todas as SEA, optou-se, neste estudo, problematizar apenas duas destas. A escolha das SEA se deu em função das distinções per- 
ceptíveis em termos de projeções nos elementos constitutivos em cada aula das respectivas Sequencias de Ensino Aprendizagem. Justifica-se essa seleção pelo fato que os dois materiais didáticos abordam praticamente os mesmos contextos e conceitos. A SEA Termoquímica I e Termoquímica II apresentam como temática o uso dos combustíveis e tratam dos conceitos pertencentes a termoquímica, como calor, temperatura, reação de combustão e entalpia, por exemplo.

Os quadros 1 e 2 apresentam uma relação dos elementos constitutivos de cada uma das aulas das duas SEA, destacam também os objetivos propostos nessas aulas e possíveis projeções no Losango Didático que cada aula apresenta.

Quadro 1. Elementos constitutivos da SEA Termoquímica I de acordo com os eixos (epistemológico e pedagógico) e possíveis projeções no Losango Didático

\begin{tabular}{|c|c|c|c|}
\hline \multicolumn{4}{|c|}{ SEA Termoquímica I - Combustíveis e Energia } \\
\hline Aulas & Elementos do eixo epistemológico & $\begin{array}{l}\text { Aspectos do eixo } \\
\text { pedagógico }\end{array}$ & $\begin{array}{l}\text { Situação em } \\
\text { relação os } \\
\text { quadrantes }\end{array}$ \\
\hline A1 & $\begin{array}{l}\text { - Texto informativo de abertura tratando } \\
\text { da temática combustíveis, destacando } \\
\text { comparativamente os tipos de combustíveis } \\
\text { (por exemplo, álcool e gasolina). O mesmo } \\
\text { texto, também abordando aspectos ambientais } \\
\text { do uso de combustíveis; } \\
\text { - Questões problematizadoras tratando dos } \\
\text { conceitos de calor e temperatura, saldos } \\
\text { energéticos nas combustões de combustíveis e } \\
\text { previsão das quantidades de produtos gerados } \\
\text { nas combustões. }\end{array}$ & $\begin{array}{l}\text { - Apresentar tema gerador } \\
\text { partindo da leitura e } \\
\text { discussão do texto; } \\
\text { - Identificar as ideias } \\
\text { prévias dos alunos } \\
\text { partindo da análise do } \\
\text { resultado das questões } \\
\text { problemas. }\end{array}$ & $\begin{array}{l}\text { Tendendo } \\
\text { ao centro do } \\
\text { losango. }\end{array}$ \\
\hline A2 & $\begin{array}{l}\text { - Experimento visando introduzir a ideia de } \\
\text { calor como forma de energia. E como ocorre a } \\
\text { transferência do mesmo; } \\
\text { - Apresentação de questões investigativas sobre } \\
\text { resultados experimentais. }\end{array}$ & $\begin{array}{l}\text { - Realização e discussão do } \\
\text { experimento; } \\
\text { - Discussão do conteúdo: } \\
\text { calor e equilíbrio térmico; } \\
\text { - Apresentação e discussão } \\
\text { de problemas durante a } \\
\text { discussão dos conteúdos. }\end{array}$ & $\begin{array}{l}\text { Tendendo } \\
\text { ao centro do } \\
\text { losango. }\end{array}$ \\
\hline A3 & $\begin{array}{l}\text { Abordagem do conceito de calor específico } \\
\text { baseado no experimento da aula } 02 \text {. }\end{array}$ & $\begin{array}{l}\text { Através do debate sobre } \\
\text { o experimento, tornar os } \\
\text { alunos capazes de aplicar } \\
\text { o conhecimento de calor } \\
\text { específico }\end{array}$ & $\begin{array}{l}\text { Na região da } \\
\text { circunferência. }\end{array}$ \\
\hline A4 & $\begin{array}{l}\text { Realização de dois experimentos para posterior } \\
\text { dedução da equação que rege o calor. Por } \\
\text { motivos de segurança o experimento foi } \\
\text { realizado de forma expositiva. }\end{array}$ & $\begin{array}{l}\text { Os dois experimentos } \\
\text { como caminho para a } \\
\text { dedução da equação } \\
\text { química } \mathrm{Q}=\text { m.c. } \Delta \mathrm{T} \text {. }\end{array}$ & $\begin{array}{l}\text { Na região da } \\
\text { circunferência. }\end{array}$ \\
\hline
\end{tabular}


Quadro 1. continuação

\begin{tabular}{|c|c|c|c|}
\hline \multicolumn{4}{|c|}{ SEA Termoquímica I - Combustíveis e Energia } \\
\hline Aulas & Elementos do eixo epistemológico & $\begin{array}{l}\text { Aspectos do eixo } \\
\text { pedagógico }\end{array}$ & $\begin{array}{l}\text { Situação em } \\
\text { relação os } \\
\text { quadrantes }\end{array}$ \\
\hline A5 & Dedução da equação química $\mathrm{Q}=\mathrm{m} . c . \Delta \mathrm{T}$. & $\begin{array}{l}\text { A partir dos experimentos } \\
\text { da aula anterior, deduzir a } \\
\text { equação química que rege } \\
\text { o calor, tornando os alunos } \\
\text { não só capazes de utilizá- } \\
\text { las, mas também conhecer } \\
\text { seu desenvolvimento, } \\
\text { método, como construí-la } \\
\text { e alterá-la. }\end{array}$ & $\begin{array}{l}\text { Tangenciando } \\
\text { a } \\
\text { circunferência } \\
\text { tendendo ao } \\
\text { quadrante } a \text {. }\end{array}$ \\
\hline A6 & $\begin{array}{l}\text { Realização e discussão do experimento de } \\
\text { determinação do calor de combustão do } \\
\text { álcool. }\end{array}$ & $\begin{array}{l}\text { Determinar o calor de } \\
\text { combustão do álcool } \\
\text { empiricamente para o } \\
\text { debate sobre a relação de } \\
\text { calor com a entalpia. }\end{array}$ & $\begin{array}{l}\text { Na região da } \\
\text { circunferência. }\end{array}$ \\
\hline $\begin{array}{l}\text { A7 } \\
\text { A8 }\end{array}$ & $\begin{array}{l}\text { Aula abordando os conceitos de Entalpia e Lei } \\
\text { de Hess. }\end{array}$ & $\begin{array}{l}\text { Relacionar através da } \\
\text { discussão calor e entalpia. }\end{array}$ & $\begin{array}{l}\text { Fora da } \\
\text { região da } \\
\text { circunferência, } \\
\text { quadrante } a \text {. }\end{array}$ \\
\hline A9 & $\begin{array}{l}\text { Aula para calcular entalpia usando a energia de } \\
\text { ligação. }\end{array}$ & $\begin{array}{l}\text { Usar energia de ligação } \\
\text { para calcular a entalpia de } \\
\text { um gás, o qual pode ser } \\
\text { usado como combustível. }\end{array}$ & $\begin{array}{l}\text { Tangenciando } \\
\text { a } \\
\text { circunferência } \\
\text { tendendo ao } \\
\text { quadrante } a \text {. }\end{array}$ \\
\hline A10 & $\begin{array}{l}\text { Aula sobre efeito estufa e maneiras de diminuir } \\
\text { seu impacto no ambiente. }\end{array}$ & $\begin{array}{l}\text { Aplicar os conhecimentos } \\
\text { para discutir o efeito estufa } \\
\text { e maneiras de diminuir } \\
\text { seus impactos no nosso } \\
\text { planeta. }\end{array}$ & $\begin{array}{l}\text { Tangenciando } \\
\text { a } \\
\text { circunferência } \\
\text { tendendo ao } \\
\text { quadrante } c \text {. }\end{array}$ \\
\hline
\end{tabular}

Fonte: elaborado pelos autores.

Verifica-se no Quadro 1 que no caso da SEA Termoquímica I, olhando detidamente para os aspectos destacados nos eixos epistemológico e pedagógico, tem-se as duas primeiras aulas do material didático tendendo ao centro da circunferência (figura 3), o que denota um equilíbrio no que tange às dimensões epistêmica e pedagógica. Isso em virtude de que a relação Contexto e Conceito seja mais perceptível, mesmo no caso da aula 2 (A2), que trata de uma atividade experimental.

Tratando das aulas A3, A4, A6 desse mesmo material didático verifica-se uma projeção dos constitutivos das aulas na região de circunferência do Losango Didático. Essa projeção é bastante importante destacar, pois trata-se de aulas que tendem a exploração mais detida da parte conceitual da SEA. Esse caso parece demonstrar que a parte conceitual esta interligada 
com as perguntas problematizadoras do contexto e atividade experimental, o que contribui para o professor promover uma interação dialógica com os estudantes. Já as demais aulas desse mesmo material didático apresentam uma projeção para fora da circunferência do losango didático, o que pressupõem aulas mais centradas no quadrante c, com atividades e estratégias que presumem ações centradas no professor e tendendo ao conhecimento científico.

Quadro 2. Elementos constitutivos da SEA Termoquímica II de acordo com os eixos (epistemológico e pedagógico) e possíveis projeções no losango didático

\begin{tabular}{|c|c|c|c|}
\hline \multicolumn{4}{|c|}{ SEA Termoquímica II - Combustíveis } \\
\hline Aulas & Elementos do eixo epistemológico & $\begin{array}{l}\text { Aspectos do eixo } \\
\text { pedagógico }\end{array}$ & $\begin{array}{l}\text { Situação em } \\
\text { relação os } \\
\text { quadrantes }\end{array}$ \\
\hline A1 & $\begin{array}{l}\text { - Texto informativo de abertura tratando da } \\
\text { temática combustíveis, considerando o uso dos } \\
\text { derivados de petróleo. Aborda ainda possíveis } \\
\text { impactos ambientais advindos dos vazamentos } \\
\text { de petróleo nos mares; } \\
\text { - Questões problematizadoras tratando dos } \\
\text { saldos energéticos nas combustões. Fontes e } \\
\text { tipos de combustíveis. }\end{array}$ & $\begin{array}{l}\text { Discutir os tipos de } \\
\text { combustíveis, como } \\
\text { produzem quantidades de } \\
\text { energias diferentes. }\end{array}$ & $\begin{array}{l}\text { Na região da } \\
\text { circunferência. }\end{array}$ \\
\hline A2 & $\begin{array}{l}\text { Apresentação de um vídeo de } \sim 8 \text { minutos, } \\
\text { no qual são apresentadas informações de } \\
\text { introdução ao conteúdo (estados físicos } \\
\text { e entalpia, e processos endotérmicos e } \\
\text { exotérmicos). }\end{array}$ & $\begin{array}{l}\text { Gerar ambiente com } \\
\text { maior interação, de modo } \\
\text { a garantir a aprendizagem } \\
\text { mais significativa, a partir } \\
\text { de uma abordagem dos } \\
\text { conceitos contidos no filme. }\end{array}$ & $\begin{array}{l}\text { Fora da } \\
\text { região da } \\
\text { circunferência, } \\
\text { quadrante } a \text {. }\end{array}$ \\
\hline A3 & $\begin{array}{l}\text { Apresentação dos conceitos de Endotérmicos } \\
\text { e Exotérmicos. }\end{array}$ & $\begin{array}{l}\text { Aula dialogada relacionada } \\
\text { ao conteúdo de processos } \\
\text { endotérmicos e exotérmicos. }\end{array}$ & $\begin{array}{l}\text { Na região da } \\
\text { circunferência. }\end{array}$ \\
\hline A4 & $\begin{array}{l}\text { Aula de laboratório, onde será realizado } \\
\text { o experimento sobre decomposição da água } \\
\text { oxigenada. }\end{array}$ & $\begin{array}{l}\text { A experimentação como } \\
\text { método que garante ao } \\
\text { professor uma maior } \\
\text { atenção do aluno para o } \\
\text { que será realizado. Com } \\
\text { objetivo de investigar o } \\
\text { calor envolvido na reação } \\
\text { de decomposição da água } \\
\text { oxigenada. }\end{array}$ & $\begin{array}{l}\text { Fora da } \\
\text { região da } \\
\text { circunferência, } \\
\text { quadrante } a \text {. }\end{array}$ \\
\hline A5 & $\begin{array}{l}\text { Após a realização do experimento, a aula } \\
\text { relacionada ao conteúdo sobre medidas de } \\
\text { calor, calorimetria e as unidades: cal, kcal, J e } \\
\mathrm{Kj}\end{array}$ & $\begin{array}{l}\text { Após a realização do } \\
\text { experimento, a aula } \\
\text { dialogada relacionada os } \\
\text { conceitos (medidas de calor, } \\
\text { calorimetria e unidades: Cal, } \\
\text { kcal, J e Kj. }\end{array}$ & $\begin{array}{l}\text { Fora da } \\
\text { região da } \\
\text { circunferência, } \\
\text { quadrante } a \text {. }\end{array}$ \\
\hline
\end{tabular}


Quadro 2. continuação

\begin{tabular}{|l|l|l|l|}
\hline \multicolumn{5}{|c|}{ SEA Termoquímica II - Combustíveis } \\
\hline Aulas & \multicolumn{1}{|c|}{ Elementos do eixo epistemológico } & \multicolumn{1}{|c|}{$\begin{array}{c}\text { Aspectos do eixo } \\
\text { pedagógico }\end{array}$} & $\begin{array}{l}\text { Situação em } \\
\text { relação os } \\
\text { quadrantes }\end{array}$ \\
\hline $\begin{array}{l}\text { A6 } \\
\text { A7 } \\
\text { A8 }\end{array}$ & $\begin{array}{l}\text { Aulas relacionadas ao conteúdo de entalpia, } \\
\text { combustão e energia de ligação. }\end{array}$ & $\begin{array}{l}\text { Aulas dialogadas relacionada } \\
\text { ao conteúdo de entalpia, } \\
\text { entalpia de combustão e } \\
\text { energia de ligação. }\end{array}$ & $\begin{array}{l}\text { Fora da } \\
\text { região da } \\
\text { circunferência, } \\
\text { quadrante } a .\end{array}$ \\
\hline A9 & Aula abordando a Lei de Hess & $\begin{array}{l}\text { Aula dialogada relacionada } \\
\text { ao conteúdo sobre A Lei de } \\
\text { Hess }\end{array}$ & $\begin{array}{l}\text { Fora da } \\
\text { região da } \\
\text { circunferência, } \\
\text { quadrante } a .\end{array}$ \\
\hline A10 & $\begin{array}{l}\text { Revisão do conteúdo dado no decorrer da } \\
\text { Sequência de Ensino Aprendizagem. }\end{array}$ & $\begin{array}{l}\text { Aula de exercício de revisão } \\
\text { do conteúdo dado. }\end{array}$ & $\begin{array}{l}\text { Fora da } \\
\text { região da } \\
\text { circunferência, } \\
\text { quadrante } a .\end{array}$ \\
\hline
\end{tabular}

Fonte: elaborado pelos autores.

A SEA Termoquímica II (Quadro 2), embora abordando a mesma temática e partes conceituais da SEA Termoquímica I, apresentam apenas as aulas A1 e A3 em situação de equilíbrio de acordo com os 4 quadrantes. As demais aulas do material didático se alinham ao quadrante "a", com aspectos nas aulas tendendo a aula centrada na ação do professor e parte conceitual. Importante frisar que essas projeções não passam de uma análise prévia desses materiais didáticos, que nada garante que tais intenções descritas nas SEA se configurem em ações concretas de sala de aula circunscritas a circunferência do modelo, nem mesmo aos quadrantes propostos por este. Contudo, apresenta um panorama de como o material didático esta se configurando de acordo com as dimensões epistêmica e pedagógica, o que pode ser um norte para o professor elaborar seu próprio material didático.

De acordo com a análise realizada das SEA conforme quadrantes do modelo Losango Didático de Méheut (2005), ficou evidenciado que os materiais desenvolvidos estão todos no quadrante que configura aproximações epistemológicas para os conhecimentos científicos e pedagógicos nas atividades centradas no professor, quadrante "a”. Essa análise possibilita inferir que a totalidade do material da ênfase ao conteúdo científico, apresentam pouca exploração do mundo material, o que presume certo distanciamento do cotidiano problematizado. De qualquer modo, em linhas gerais, este olhar permitiu inferir que as SEA estavam centradas na ação do professor com pouca interação entre os alunos e com ênfase no conhecimento científico em detrimento ao mundo material. Tal situação nos permite inferir que as SEA construídas, em que a relação conceito e contexto não é trabalhada de forma explícita e intencional, não são promotoras de aprendizagens e pouco contribuem para a superação de concepções alternativas sobre o tema abordado. 


\section{Algumas considerações}

As SEA desenvolvidas e aplicadas, quando analisadas de acordo com aproximações epistemológicas, possibilitou inferir que quase a totalidade do material dá ênfase ao conteúdo científico, apresentando pouca discussão do contextual, o que caracterizou certo distanciamento entre o mundo material (contexto) e o conhecimento científico (conceitual). Esse aspecto apenas reforçou a ideia existente no âmbito do ensino de Ciências que os professores pouco estabelecem relações de forma intencional e direcionada para estabelecer relações entre o contexto e o conceito, ou seja, entre os eixos pedagógicos e epistemológicos, o que determina abordagens com ênfase em conteúdo em sala de aula. Essa situação destacada, ao menos neste estudo, pareceu também se configurar nas primeiras vivências no âmbito do campo de estágio. Também, no ensino de Ciências as aulas são em sua grande maioria centradas no professor, com pouca dialogicidade, não valorizando a importância dos saberes dos estudantes na construção de seus percursos de aprendizagem.

Assim, há fortes evidências do quanto é necessário avançar tanto nos cursos de formação inicial quanto continuada no entrelaçamento entre Conceito e Contexto, ou seja, em uma situação de equilíbrio entre a dimensão pedagógica e epistemológica. De nosso ponto de vista, tal equilíbrio só será possível se nos cursos de formação sejam desenvolvidos junto com eles processos que levam o sujeito a adotar uma relação com o saber e não apenas a acumulação de conteúdos intelectuais. Lembrando que é na sala de aula, mundo físico e social, o local em que estas relações devem acontecer. Portanto, o professor, representante máximo desse mundo físico e social, necessita construir de maneira intencional, um modelo pedagógico relacional, que apresente também uma epistemologia relacional, semelhante ao modelo do Losango Didático proposto neste estudo.

\section{Referências}

AIKENHEAD, G. S. The social contract of science: implications for teaching science. In: SOLOMON, J.; AIKENHEAD, G. (Ed.). STS education: international perspectives on reform. New York: Teachers College Press, 1994. p. 47-59.

AULER, D. Alfabetização cientifico-tecnológica para que? Ensaio: pesquisa em educação em ciências, Belo Horizonte, v. 3, n. 1, p. 122-134, 2001.

AULER, D. Enfoque ciência-tecnologia-sociedade: pressupostos para o contexto brasileiro. Ciência \& Ensino, Piracicaba, v. 1, n. esp., p. 1-20, 2007.

BACHELARD, G. A formação do espírito científico. Rio de Janeiro: Contraponto, 1996.

BURBULES, N.; LINN, M. Science education and philosophy of science: congruence or contradiction? International Journal of Science Education, London, v. 13, n. 3, p. 227-241, 1991. 
Silva, E. L.; Wartha, E. J.

CACHAPUZ, A. et al. Uma visão sobre o ensino das ciências no pós-mudança conceptual: contributos para a formação de professores. Inovação, Lisboa, v. 13, n. 2/3, p. 117-137, 2000.

CHARLOT, B. Da relação com o saber, elementos para uma teoria. Porto Alegre: Artmed, 2000.

CHARLOT, B. Relação com o saber, formação dos professores e globalização. Porto Alegre: Artes Médicas, 2005.

DELIZOICOV, D.; ANGOTTI, J. A. Física-formação geral. São Paulo: Cortez, 1991.

DRIVER, R. Students' conceptions and the learning of science. International Journal of Science Education, London, v. 11, n. 5, p. 481- 490, 1989.

DRIVER, R. Pupil's alternative frameworks in science. International Journal of Science Education, London, v. 3, n. 1, p. 93-101, 1981.

FERNÁNDEZ, I. Análisis de las concepciones docentes sobre la actividad científica: una propuesta de transformación. 2000. Tesis (Doctoral) - Departament de Didàctica de les Ciencies Experimentals, Universidad de Valencia, Valencia, 2000.

FLORENTINO, A. Fundamentos da educação 1. Rio de Janeiro: Fundação Cecierj, 2004. FREIRE, P. Ação cultural para a liberdade e outros escritos. 10. ed. Rio de Janeiro: Paz e Terra, 2002.

FREIRE, P. A educação na cidade. 6. ed. São Paulo: Cortez, 2005.

HAMMER, D. Epistemological considerations in teaching introductory physics. Science Education, Hoboken, v. 79, n. 4, p. 393-413, 1995.

LEDERMAN, N. G. Students' and teachers' conceptions of the nature of science: a review of the research. Journal of Research in Science Teaching, Hoboken, v. 29, n. 4, p. 331-359, 1992.

LUTFI, M. A abordagem sociológica do ensino de química. Ciência \& Ensino, Piracicaba, n. 3, p. 7-9, 1997. Disponível em: <http://200.133.218.118:3535/ojs/index.php/ cienciaeensino/article/view/22/28>. Acesso em: 25 abr. 2018.

LUTFI, M. Cotidiano e educação em química: os aditivos em alimentos como proposta para o ensino de química no $2^{\circ}$ grau. Ijuí: Ed. Unijuí, 1988.

LUTFI, M. Os ferrados e os cromados: produção social a apropriação privada do conhecimento químico. Ijuí: Ed. Unijuí, 2005.

MACHADO, A. H. Aula de química: discurso e conhecimento. Ijuí: Ed. Unijuí, 1999.

MALDANER, O. A. A formação inicial e continuada de professores de química: professor / pesquisador. 2. ed. Ijuí: Ed. Unijuí, 2003. 
Estabelecendo relações entre as dimensões pedagógica e epistemológica ...

MATTHEWS, M. R. Un lugar para la historia y la filosofía en la enseñanza de las ciencias.

Comunicación, Lenguaje y Educación, Madrid, n. 11-12, p. 141-155, 1991.

MÉHEUT, M. Teaching-learning sequences tools for learning and/or research. In:

BOERSMA, K. et al. (Ed.). Research and quality of science education. Dordrecht:

Springer, 2005. p. 195-207.

MÉHEUT, M.; PSILLOS, D. Teaching-learning sequences: aims and tools for science education research. International Journal of Science Education, London, v. 26, n. 5 , p. $515-535,2004$.

POZO, J. I.; CRESPO, M. A. A aprendizagem e o ensino de ciências: do conhecimento científico ao conhecimento cotidiano. Porto Alegre: Artmed, 2009.

SILVA, E. L.; MARCONDES, M. E. R. Materiais didáticos elaborados por professores de química na perspectiva CTS: uma análise das unidades produzidas e das reflexões dos autores. Ciência \& Educação, Bauru, v. 21, n. 1, p. 65-83, 2015. Disponível em: < http:/ / dx.doi.org/10.1590/1516-731320150010005>. Acesso em: 25 abr. 2018.

SILVA, E. L.; MARCONDES, M. E. R. Visões de contextualização de professores de química na elaboração de seus próprios materiais didáticos. Ensaio: pesquisa em educação em ciência, Belo Horizonte, v. 12, n. 1, p. 101-118, 2010.

SOLOMON, J.; DUVEEN, J.; SCOTT, L. Pupils' images of scientific epistemology. International Journal of Science Education, London, v. 16, n. 3, p. 361-373, 1994.

SONGER, N. B.; LINN, M. C. How do students' views of science influence knowledge integration? Journal of Research in Science Teaching, Hoboken, v. 28, n. 9, p. 761-784, 1991.

SOUZA, F. L.; MARCONDES, M. E. R. Interações verbais e cognitivas em aulas de química contextualizadas. Revista Brasileira de Pesquisa em Educação em Ciências, Belo Horizonte, v. 13, n. 3, p. 95-119, 2013.

TABER, K. S. Building the structural concepts of chemistry: some considerations from education research. Chemistry Education: research and practice in Europe, Ioannina, v. 2, n. 2, p. 123-158, 2001.

TEODORO, S. R. A história da ciência e as concepções alternativas de estudantes como subsídios para o planejamento de um curso sobre atração gravitacional.

Dissertação (Mestrado em Educação para a Ciência) - Faculdade de Ciências, Universidade Estadual Paulista "Júlio de Mesquita Filho”, Bauru, 2000.

VIENNOT, L. Spontaneous reasoning in elementary dynamics. European Jornal of Science Education, London, v. 4, n. 2, p. 205-221, 1979.

WATTS, D. M.; ZYLBERSZTAJN, A. A survey of some children's ideas about force. Physics Education, London, v. 16, p. 360-365, 1981. 
Silva, E. L.; Wartha, E. J.

WARTHA, E. J.; SILVA, L. E.; BEJARANO, R. R. N. Cotidiano e contextualização no ensino de química. Química Nova na Escola, São Paulo, v. 35, n. 2, p. 84-91, 2013.

YAGER, R.; PENICK, J. E. School science in crisis. Curriculum Review, Chicago, v. 22, n. 3, p. $67-70,1983$.

Artigo recebido em 22/07/2017. Aceito em 05/11/2017.

Contato: Universidade Federal de Sergipe, Departamento de Química, Av. Marechal Candido Rondon, Jardim Rosa Elza, São Cristovão, SE, CEP 49100-000, Brasil. 